\title{
Development of organisation and planning in animal breeding: II. A review on breeding planning
}

\author{
Pera Herold ${ }^{1,2}$, Regina Rößler ${ }^{1,3}$, Helmut Momm and Anne Valle Zárate ${ }^{1}$ \\ 'Institute of Animal Production in the Tropics and Subtropics, University Hohenheim, Stuttgart, Germany, ${ }^{2}$ Landesamt \\ für Geoinformation und Landentwicklung, Kornwestheim, Germany, ${ }^{3}$ Kuratorium für Technik und Bauwesen in der \\ Landwirtschaft, Darmstadt, Germany
}

\begin{abstract}
Breeding planning resp. planning of breeding measures as scientific discipline within animal breeding science has developed in close connection to quantitative genetics in the middle of the last century. From the beginning, breeding planning was mainly focussed on macroeconomic resp. national targets. This viewpoint has been maintained until today. This is in conflict with existing business oriented organisational structures in animal breeding. The present study gives an overview on the development of breeding planning. Based on five recent works on breeding planning it is shown that approaches have already been developed that allow for taking micro- and macroeconomic aspects into account when looking into the organisational structures. Building on these examples, the study aims at working out further approaches to breeding planning based on enterprise resource, supply chain and value added chain planning. Breeding planning combined with consideration of organisational structures and, where necessary, with organisational analysis allows to take the requirements of the private and the public sector into account. Thereto new research fields open up within animal breeding science.
\end{abstract}

Keywords: animal breeding, breeding planning, enterprise resource planning, supply chain planning, value added chain planning

\section{Introduction}

Breeding planning has developed since the middle of the last century. A first pathbreaking study is "Animal Breeding Plans" by Lush (1945) which is based on the then newly developed quantitative genetics. In this first stage of breeding planning, mainly studies on optimising genetic parameters are characteristic. In a next step, economic parameters were included in the studies. In both planning approaches, national macroeconomic breeding programs are assumed with genetic gain benefiting common welfare. This generalised planning approach has been maintained in principle until today. Looking at the nowadays very much differentiated organisational structures in animal breeding as illustrated by Herold et al. (2012) this approach misses out the requirements of the private sector.

The aim of the present study is to point out the discrepancy between the previous methods in breeding planning and the actual requirements, which are derived from the existing organisational structures in animal breeding. Solutions for breeding planning 
adapted to actual practice in breeding are presented. The results are derived in consideration of economic planning procedures like enterprise resource planning systems or supply chain planning. Starting point is the definition of the term and the development of breeding planning measures. Thereafter, a review of newer developments in breeding planning and attempts for further development is presented. Finally, possible further developments in breeding planning and related global and regional challenges are discussed.

\section{Term and development of planning of breeding measures}

Breeding planning combines all measures for developing and optimising breeding programmes. It is always future-orientated, modelling breeding programs (breeding plans) for the coming marketing situation. Planning - the planning and definition of an objective and goal-setting - as well as the search for alternative plans, the decision for a breeding programme, its implementation and monitoring are counted among the primary functions of management. To this extent, the planning represents an important phase within the management process in the private and public area. Especially on breeding planning, Börner et al. (1981) have described a detailed management process, which serves for orientation as a phase scheme.

Planning of animal breeding measures with the inclusion of monetary variables when assessing the future breeding progress has become popular since the end of the 1960s. Zeddies (1973) and Brascamp (1978) gave a broad overview on this topic. The approach introduced by Niebel (1973) included a system analysis. Deterministic calculations in connection with the net present value method allowed for an optimisation of breeding programmes. Zeddies \& Weniger (1970) presented another approach. They combined the net present value method with linear programming. With that, the optimum could be determined even clearer than with Niebel's method (1973), as threshold values could be determined for all features within the breeding programme. However, already Zeddies (1973) and Brascamp (1978) pointed out that the cost-benefit analyses in breeding planning are contrary to the investment calculation of private enterprises. In breeding planning, the starting point are national breeding programmes. In the end, the selection progress is common good of the general public, for example, in the form of cheaper products thanks to increased animal performances. This means that the breeders' or breeding organisations' individual good is subordinate to the common good. Brascamp (1978) points out that for an insemination station the decisive point is not the discounted costs of breeding, as they are calculated in breeding planning, but the actual costs and the expected sale of sperm portions or the revenue.

In breeding planning, a general distinction is made between deterministic and stochastic simulations. Karras (1984) developed a computer-based breeding planning programme ZPLAN - that calculates the genetic gain and various economical and investment parameters. This breeding planning programme, which operates on the basis of deterministic simulations, was further developed by Nitter \& Graser (1994). Documentation in English language made the programme available to an international circle of users (Nitter et al. 2000). The programme as well as the documentation are being continuously expanded and updated (Willam et al. 2008). A newer development allows for the calculation of increase in inbreeding (Karras 2010). A further development of this software for commercial utilisation is released on the market under the name ZPLAN+. For features of this programme see Täubert et al. (2010). 
Towards the end of the 1970s, Niebel and Fewson examined breeding planning for purebreeding of dual-purpose cattle breeds within six publications (e.g. Niebel \& Fewson 1976) as well as the optimisation of breeding planning in pigs within four publications (e.g. Niebel \& Fewson 1979). The breeding programmes modelled at that time are still being applied, with small changes only for parameters such as testing methods, extent of performance testing, use of young bulls in the testing area as well as the transfer of the genetic gain to the production level. Additional works deal with the significance of relative economic weighing of traits within the breeding programmes as well as with breeding planning in crossbreeding programmes (e.g. Wolfová et al. 2001, Wolfová \& Nitter 2004). ZPLAN has been used for breeding planning in various livestock species, such as cattle (e.g. Kahi 2000, Willam et al. 2002, Harder et al. 2004), pigs (e.g. Wuensch 1998), sheep (e.g. Müller 1994) and goats (e.g. Zumbach \& Peters 2007). In the last years, planning of animal breeding measures with ZPLAN has been also increasingly used for low-input systems (e.g. Nakimbugwe 2005, Wurzinger et al. 2008, Roessler et al. 2009) and in context with organisational issues (Roessler 2009, Rewe et al. 2010). Recently, many publications on breeding planning are dealing with the introduction of genomic selection in cattle breeding (König et al. 2009, Karras et al. 2011, Neuner \& Götz 2011).

Beside the programme ZPLAN, there is other software, such as the programme SelAction (Rutten \& Bijma 2001, Rutten et al. 2002) that uses a deterministic approach to evaluate the selection response in livestock breeding programmes (genetic gains in individual breeding objective traits in the population, breeding progress within the selection groups) considering the rate of inbreeding within the monitored population. However, it does not provide the option for an economic assessment of the monitored breeding plans. The modelling programme SelAction has been used for the evaluation of breeding programmes for various species of livestock, e.g. poultry (Zerehdaran et al. 2009), pigs (Knol \& Prins 2004), cattle (Hinrichs et al. 2008) and sheep (Swan et al. 2009).

Another development in breeding planning is the stochastic simulation as, for example, applied by Dekkers\&Shook (1990). Contrary to the deterministic simulation, itallows examining overlapping generations. However, the large volumes of data allow only simulating one trait at a time. Dekkers \& Shook (1990) are not looking into a national breeding programme, but rather the situation in an artificial-insemination station which must maintain its stand in a competitive market. This approach away from the national breeding programme towards breeding planning for individual companies marks the works of these authors (Dekkers 1992, Dekkers et al. 1996, Dekkers \& Gibson 1998, Shook 2006).

\section{Newer developments in the planning of breeding measures}

Below, a selection of five newer works on breeding planning is presented in more detail. The first three are based on studies for individual breeding organisations, while the last two can be allocated to the national or macroeconomic area.

König (2001) investigated how breeding associations can design cost-effective and efficient breeding programmes. In German dairy cattle breeding, the competition between breeding companies for market shares in the area of insemination keeps increasing. In his opinion, small breeding programmes are no longer competitive in view of the process of 
increasing globalisation. After König (2001), the number of bulls with breeding values above a certain market benchmark, the prices for the sperm of these bulls, and the number of sold sperm portions determine the market share of a breeding and insemination company. The number of marketable bulls is determined by the overall number of test bulls, the number of daughters per test bull, as well as the selection criteria of the parents. König (2001) listed a number of issues which a breeding organisation must deal with, in order to increase its efficiency and competitiveness:

- Integration of the latest innovations in molecular genetics and biotechnology;

- consequent utilisation of superior bulls from other countries in combination with central testing of the bull dams;

- optimisation of the bull dam selection in the field;

- introduction of the test herd principle for progeny testing.

König (2001) concentrated his work mainly on the estimation of trends in genetic parameters. For the aspect of the bull dam selection, cost-benefit calculations are performed, following the approach of traditional planning of animal breeding measures: Factors influencing the breeding progress are evaluated and optimised.

Further, König et al. (2007) examined the success of German insemination organisations for cattle looking at the selection intensity in the path of the dams' sires, by calculating the ratio of the realised selection intensity and the expected selection intensity (control value). They observed that insemination stations with high control values are very successful in the national competition when compared to the national listings of top bulls, independently of the size of the cattle population considered. In addition to that, the control value allows the assessment of partial breeding values when making the selection decision for a bull. The authors concluded that the respective control instruments will gain increasing significance in future in order to double-check selection decisions and develop efficient selection strategies. The method presented by König et al. (2007) extends beyond the present approaches of breeding planning and explores how decisions related to the breeding planning can be documented with their consequences, and controlled. Innovative is the feature that the decision of the breeding company (selection of sires) is connected with the actual decision of the breeders (realised selection intensity).

The study of Grandke (2002) deals with methods and models of breeding planning and models for the strategic control of contemporary breeding companies. The objective of the work was to develop instruments with which breeding companies can combine the controlling of the business economics and the breeding programmes. Grandke (2002) argued that, in future, breeding companies will not only have to deal with the optimisation of the population parameters, but also have to put the economic operation of breeding programmes and breeding companies a priori. Breeding programmes are not restricted to a closed population only, as breeding companies are nowadays active in a global environment. On the basis of the shareholder-value approach, Grandke (2002) designed a model for the value chain analysis of breeding programmes, which serves to determine future developments of economical targets. On the example of a particular company, he examined seven strategy alternatives and within each alternative three different scenarios - best case, reference case, and worst case. As the most important criterion for success, the number of first-time inseminations is determined; their decline having the greatest influence 
on the economic success of the breeding company. For the presented example company, the greatest success is achieved through the co-operation or, fusion with other breeding associations, as they yield the greatest cost advantages. Further, it becomes obvious that one-time strategic actions do not ensure long-term success, but that long-term success can be only secured by the combination of different measures and continuous evaluation and adjustment.

Herold et al. (2010) examined possibilities for establishing pig breeding and supply chains in remote mountainous regions of Northern Vietnam. The study consists of three parts:

- Evaluation of the breeding managements as well as smallholder farmers' breed and trait preferences for pigs;

- evaluation of different crossbreeding schemes for the production of lean meat;

- development of optimised organisational structures for pig breeding and marketing of the generated products.

In the examined region, the local Ban breed comes second after the improved local Mong Cai breed. The farmers appreciate Ban pigs for their broad fodder spectrum, feed intake capability, resistance against diseases, health and sturdiness, fast growth as well as carcass quality. In all modelled crossbreeding schemes, there were only small genetic gains achieved; the Yorkshire $\times$ Ban crossbreeding scheme showing the highest, but still small genetic gains. The traditional production and fattening of the exotic boar $\times$ local sow breed does not require any particular organisational set-ups. This system already exists in a form improvised by the farmers. The advantage of an organised system would be, in particular, the controlled conservation of the local genetic resources. For this purpose, a stratified crossbreeding scheme, as the authors have modelled it, would be interesting: In the villages far away from the market, the local Ban breed is kept as a purebreed. Ban boars are brought to the villages that are closer to the market for crossing with Mong Cai sows. The F1-gilts are transferred to the villages closest to the market where terminal crossings with Yorkshire boars produce piglets for fattening and slaughter. A short food supply chain is recommended as an innovative approach to organisation. This system connects remote villages and livestock populations with those close to the market. Critical issues of the organisation planning such as poorly developed infrastructure as well as poor access to the buyers, the markets and information are addressed. In the villages close to the market, the co-operation with slaughterhouses is envisaged in order to secure regional marketing. The farmers from different villages form a co-operative, acting as producer group. This facilitates that the profit at the end of the chain can be returned to all the members of the chain. In this work, it was the first time that the breeding and marketing stages for end products were combined. The vertical integration shall strengthen the identification of the breeders and animal owners with the breeding and marketing programme, and lower the transaction costs.

Bett (2009) dealt with the design and evaluation of breeding strategies for dairy goats in extensive production systems in Kenya. After describing the starting situation in Kenya, the breeding objectives and breeding methods in dairy goat production were examined. In addition to that, the institutions involved in dairy goat breeding in Kenya and interest groups in the area of breeding and management for the goat owner, as well as the effectiveness of supporting services were analysed. Starting from these studies, various scenarios of breeding objectives and their possible economic effects on individual organisations were examined; 
further, the concepts of alternative breeding plans for village breeding programs were evaluated. This work combines the classic approach to breeding planning - the juxtaposition and assessment of alternative breeding plans - with methods of organisation research and the economic evaluation of breeding objective traits. The formulation and evaluation of alternative breeding plans follows a deterministic approach. The applied software program is SelAction (Rutten et al. 2002). Bett showed in his work how a breeding programme for dairy goats could be set up. He repeatedly emphasised that the further development of dairy goat breeding and husbandry in peasant structures will only be successful if the existing informal markets are transformed to formal markets in order to ensure marketing opportunities.

\section{Approaches to further development of breeding planning}

Approaches to further develop breeding planning in the private area have to consider business planning. For the public area, political planning must be incorporated. Public breeding enterprises have to compete on the market just as private breeding companies and therefore, business planning is applicable for them, too. For business planning, complex planning systems are relevant. Planning systems have been well established in business planning already since the last quarter of the past century. Timmermann (1975) explained on the example of a simplified structural model that a planning system is required to be integrated in businesses, and how it can be developed. The issue has further been addressed e.g. by Hill (1971), Grochla (1975) and Koch (1982).

In the structural model introduced by Timmermann (1975), it is emphasised that business planning usually begins with the marketing plan or the planning of marketing measures. The marketing plan is drawn in terms of marketing volumes for each product or each product group in the planning period. It includes prognoses and assumptions. From the marketing plan, multiplying volumes with sales prices can derive the sales plan. For financing of the turnover (T) achieved in the sales process, a certain amount of capital (C) has to be invested. From the experience of the past accounting period a certain speed of capital turnover $(\mathrm{s})$ is assumed. If the turnover is divided by the speed of capital turnover, the capital need in the finance plan required for the financing of the marketing process can be determined $(C=T / s)$. For the financing of the marketing process, the capital requirement for the financing of the investment process of the company is added as a second component of the finance plan. The investment volume results from the capacity plan, which can also be derived from the marketing plan via the production plan, too. The financing needs for the sales process and the financing needs for the investment process together constitute the finance plan. Other partial plans that are to be integrated are, according to Timmermann (1975), the production plan, the staff plan, the purchase plan, the cost and profit plan, as well as the collection of information and alternative calculation.

This simple approach to explaining a planning system in businesses can be supplemented with a model taken from rather contemporary literature on business planning, and transferred to animal breeding. The outlined model has been taken from the Enterprise Resource Planning systems (ERP systems) (for example, Albert \& Fuchs 2007, Lehner et al. 2008). These systems aim to achieve that the existing resources of a company are used as efficiently as possible, and are optimised for the business processes. ERP systems are a complex application software to support the resource planning of a company and, if possible, beyond the limits of the 
company. Thanks to the systematic nature of ERP systems, it is easy to demonstrate advanced business planning in an impressive way. ERP systems reflect all relevant areas and support integration by means of central, comprehensive administration of data. This helps to avoid redundancies and supports all operating processes within a company. Besides planning, such software systems also fulfil controlling and monitoring tasks. Typical functional areas of ERP systems are material management, production, finance and accounting, controlling, research and development, sales and marketing, staff management and master data management.

When the typical functional areas of ERP systems are applied to animal breeding, particularities will appear. They are addressed on the examples of the classic core functions "acquisition", "production" and "marketing" of a breeding company (Momm 1972). The core function "acquisition" includes all activities necessary to provide the company with all required means. With regard to breeding, the starting materials to be procured are data for the breeding work, which can be, among others, results of performance and quality testing, breeding value estimation, and biotechnological and genetic analyses. Beside the own organisation, various other institutions are potential suppliers of data, for example, performance testing stations, contractors with large stock numbers, slaughterhouses, institutions responsible for breeding value estimation, and laboratories for genomic analyses. Breeding does not only constitute the nature of production, but at the same time, the nature of product development. The marketing of the breeding products has the particularity that it can be done introvertly (in particular, in the case of co-operative breeding companies). Depending on the marketing strategy, which can start out either from the results of the marketing research or of the market research, the breeding objectives are determined. In this context, the breeding objectives are likely to include traits that are valued on the market.

The trends of contemporary breeding companies towards vertical and horizontal integration or co-operation, include the utilisation of advanced business planning. Figure 1 illustrates the addressed ERP system: it indicates the three planning areas - the ERP system, the ERP-II system, and Supply Chain Planning.

Supply Chain Planning

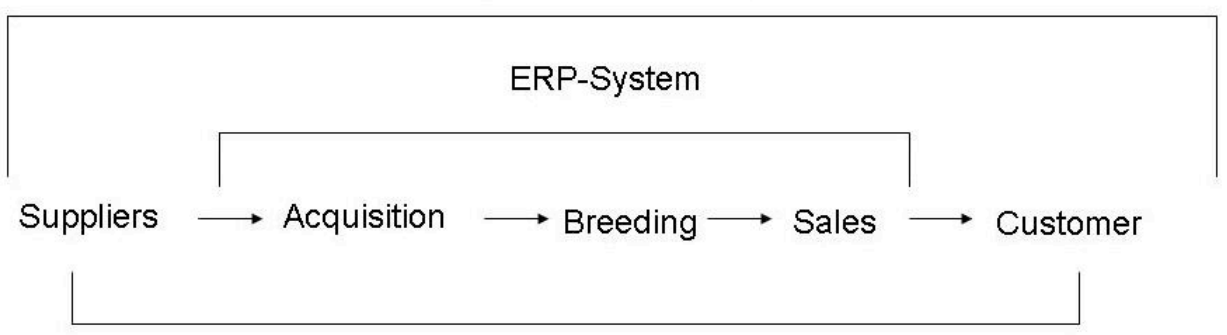

ERP-II-System

Source: Modified after Albert and Fuchs (2007)

Figure 1

ERP system, expanded by cross-company functions 
In ERP, the planning and control of company-internal resources are based on integrated data administration. The ERP system refers mainly to breeding-related functions and is connected with the core areas of the company in a holistic approach. Hence, not only the breeding process of the company is reflected, but according to the definition, all other relevant areas within the company. In the ERP-II system, there is an additional exchange of information between companies as well as cross-function planning and control. This can include particular suppliers as well as customers. It is supported by cross-company co-operation and focussing at cross-company processes. The data develop internally, within the breeding companies, as well as by cross-company co-operation, for example, with institutions for performance and quality testing, producer groups and slaughterhouses.

Further, there is Supply Chain Planning, which covers cross-company planning tasks within the entire value chain, which can reach, for example, from the breeding company to the trading company for finished animal products. This task is supported by Advanced Planning and Scheduling (APS) systems for integrated planning and controlling of cross/ company business processes. The APS systems are usually added on top of existing ERP systems. APS and ERP systems are, to a high degree, dependent on each other and rely on close interaction. Williamson (2008) examines the transaction cost approach and supply chain management. While the transaction cost approach examines individual transactions, the supply chain management focuses on a whole system. Still, Williamson (2008) shows that both approaches share a lot of common ground.

In animal breeding the political planning must be taken into consideration, too. Political planning mainly aims at the objective to optimise government support measures. These support measures do not only include financial allowances, but can be provided in a non-monetary form, such as laws, directives, regulations, and a series of other measures. Political planning shall prevent haphazard support, such as of breeding companies with a strong lobby. As a principle, public means are distributed to competing types of use, such as the support of performance and quality testing, the conservation of genetic resources and increase of production efficiency by import subsidies for high-performance breeds. A classic planning method for political planning is the cost-benefit analysis, which attempts to measure and evaluate the costs as well as benefits in (discounted) monetary units. If the benefits weigh higher in a particular public project in animal breeding, in comparison to other projects, this project is most likely to meet the requirements of the macro-economic welfare criterion and should therefore be implemented. With that, this planning approach is fundamentally different from business planning. Another planning framework is introduced by Mburu \& Birner (2002) and Birner \& Wittmer (2004): Governance structures are investigated from the private and society's perspective for different examples (community wildlife sanctuaries in Kenya and decentralisation and devolution in natural resource management), and inter-organisational efficiency and efficient boundaries of the state are calculated. This methodology is based on transaction-costs economics and links the political planning with organisational analysis. 


\section{Discussion}

The presented newer works on breeding planning demonstrate tendencies to include the micro-economic reality of breeding and the existing organisational conditions. For example, the works by König (2001), König et al. (2007) and Grandke (2002) explicitly refer to the microeconomic reality of breeders' associations and artificial-insemination stations. The approaches to breeding planning of the own workgroup (among others, Roessler 2009, Herold et al. 2010) and the present study are most close to the work by Grandke (2002). This is true in particular for Grandke's (2002) view of the value chain analysis of breeding programmes by means of expected developments of micro-economic targets. This approach can be recommended for integrational and/or co-operative forms as discussed in this study, with their diverse possibilities of value chains, also beyond the analysis of breeding programmes. The approach developed by Herold et al. (2010) to combine a breeding programme with a small food supply chain demonstrates possibilities how breeding programmes could be established also in socalled disadvantaged regions and how the identification of the breeders with the breeding programme could be promoted via the integration of downstream processing and marketing stages. The work by Bett (2009) can be classified to the national respectively macroeconomic area giving an interesting impulse for breeding planning. Altogether it is concluded that, by now, also the private area has mainly applied the principle of the cost-benefit analysis for animal breeding measures in a simplified way, thus hardly satisfying the actual planning need of the respective organisation.

Therefore, this study contrasts earlier and newer works about breeding planning with the conclusion that today, breeding organisation exists in strongly different forms and has the tendency to even further diversify in its development. This assumption requires, correspondingly, different specific approaches to breeding planning. For breeding planning, any affecting organisational structure in the private as well as public area is considered a framework condition that needs to be taken into account.

In future, breeding planning will be most probably stronger included in complex planning systems, as described here, with their typical partial areas such as marketing and financing. The controlling part will increase and with that, the manageability of organisations will improve thanks to the co-ordination of planning and control, and the supply of information (Horváth 2009). This is a development which appeals to the dynamics and complexity of the business world, but increasingly suppresses any long-term planning as it has been generally recommended to the animal breeding industry, in order to achieve long-term breeding goals. The consequences are short-term loss of balance and frequent changes in the breeding plans, which counteract the principle of sustainability, which is particularly important in animal breeding. Further, in the future of breeding planning, the phase of the implementation of the plan should become more important, as it provides information which can significantly contribute to faster plan adjustments or to an increased planning efficiency.

Lately, there have been various approaches based on breeding planning, mainly in developing countries, aiming to achieve effective breeding in smallholder production systems. Most of such projects have a bottom-up approach: First, the production systems are characterised and the role of the animals within the system is evaluated (for example Lemke 2006, Kaufmann 2007, Warui 2008). Newer approaches additionally apply a method of developing breeding objectives and calculating economic values for non-marketable traits, 
based on surveys among the local animal owners. For the theoretical approach see Olesen et al. (2000) and Roosen et al. (2005). This method was, for example, applied with pigs in Vietnam (Roessler et al. 2008), Ilamas in Bolivia (Markemann \& Valle Zárate 2009, Markemann et al. 2009) and Ankole cattle in Uganda (Wurzinger et al. 2008). These user-defined breeding goals are the starting point for setting up community breeding programmes. The focus of community breeding programmes is on the participation of the individual animal owners in a regionally limited breeding programme (Olivier et al. 2002, Valle Zárate 1996, Valle Zárate \& Markemann 2010). Bett (2009) developed the concept of a community breeding programme for dairy goats for local conditions (low-input system). In his work, breeding planning is closely linked to the given institutional framework of goat breeding in Kenya. Also, the success of the evaluated breeding plans is linked to successful establishment of formal markets. This is in line with the supply chain approach presented here.

With the increasing competition of breeding organisations on a world wide level, the demands on animal breeding are growing diverse and complex: Breeding programmes are carried out on an international level, different breeding organisations are competing with each other or are interlinked in different systems of integration or alliances. For them, the profit of the individual organisation is important. Otherwise, society has a growing concern on topics related to animal breeding, e.g. conservation of animal genetic resources, animal welfare, and animal product safety. Consequently, there is always a share of public interest in animal breeding. The conflicts between private and public interests in animal breeding have to be incorporated into the discipline of breeding planning. Also, they influence the organisational feasibility. A breeding organisation will only adapt a new breeding program if it promises not only high genetic gain in the target traits but also the placing of top sires in national and/ or international high ranking lists. The society will only agree to and financially support animal breeding programmes and breeding organisations, which ensure the compatibility with public aims. An integrated approach of breeding planning and organisational analysis based on resource planning systems and new institutional economics opens up new fields of research in animal breeding science and allows for balancing demands of both, the private and public sector.

\section{Acknowledgements}

The authors thank Regina Birner for her valuable comments concerning the application of new institutional economic approaches. Financial support of the Ministry of Rural Affairs and Consumer Protection of Baden-Württemberg (MLR) is acknowledged.

\section{References}

Albert C, Fuchs C (2007) [Distinguish within the definition jungle in business software]. Professorship for Business Economics and Business Informatics, Univ Würzburg, Germany [in German]

Bett RC (2009) Design and evaluation of breeding strategies for low input dairy goat production systems in Kenya. Schriften zur internationalen Agrarentwicklung 58, Verlag Dr Koester, Berlin, Germany

Birner R, Wittmer $\mathrm{H}$ (2004) On the "efficient boundaries of the state«: the contribution of transaction-costs economics to the analysis of decentralization and devolution in natural resource management. Environ Plann C Gov Policy 22, 667-685 
Börner HJ, Momm H, Fewson D (1981) [Organisation of breeding planning]. Züchtungsk 53, 81-92 [in German]

Brascamp EW (1978) Methods on economic optimization of animal breeding plans. Rep. B-134. Research Institute for Animal Husbandry "Schoonoord", Zeist, The Netherlands

Dekkers JCM (1992) Structure of breeding programs to capitalize on reproductive technology for genetic improvement. J Dairy Sci 75, 2880-2891

Dekkers JCM, Shook GE (1990) Economic evaluation of alternative breeding programs for commercial artificial insemination firms. J Dairy Sci 73,1902-1919

Dekkers JCM, Gibson JP (1998) Applying breeding objectives to dairy cattle improvement. J Dairy Sci 81 (Suppl 2),19-35

Dekkers JCM, Vandervoort, GE, Burnside EB (1996) Optimal size of progeny groups for progeny-testing programs by artificial insemination firms. J Dairy Sci 79, 2056-2070

Grandke R (2002) [Methods and models for strategic steering of modern breeding organisations]. Habilitation, Univ Gießen, Gießen, Germany [in German]

Grochla E (1975) [Business planning and information systems]. Verlag Reinbeck bei Hamburg, Germany [in German]

Harder B, Junge W, Bennewitz J, Kalm E (2004) Investigations on breeding plans for organic dairy cattle. Arch Tierz 47, 129-139

Herold P, Rößler R, Valle Zárate A, Momm H (2012) Development of organisation and planning in animal breeding: I. A review on breeding organisation. Arch Tierz 55, 402-414

Herold P, Roessler R, Willam A, Momm H, Valle Zárate A (2010) Breeding and supply chain systems incorporating local pig breeds for small-scale pig producers in Northwest Vietnam. Livest Sci 129, 63-72

Hill W (1971) [Enterprise planning]. Sammlung Poeschel, Reihe I P 46, 2nd ed., Poeschel Verlag Stuttgart, Germany [in German]

Hinrichs D, Bennewitz J, Tetens J, Thaller G (2008) [Simulation on the consequences of genomic selection in a cattle breeding programme]. Züchtungskunde 80, 443-451 [in German]

Horváth P (2009) Controlling. 11th ed., Verlag Franz Vahlen, München, Germany

Kahi AK (2000) Genetic and economic aspects of breeding for dairy production in Kenya. Verlag Grauer, Beuren/Stuttgart, Germany

Karras K (1984) [ZPLAN software programme for optimising breeding planning in livestock]. Institute of Animal Husbandry and Animal Breeding, Univ Hohenheim, Stuttgart, Germany [in German]

Karras K (2010) [ZPLAN software programme for optimising breeding planning in livestock]. Landesamt für Geoinformation und Landentwicklung, Kornwestheim, Germany [in German]

Karras K, Herold P, Hamann H, Weidele A, Valle Zárate A (2011) [Genomic selection in Brown Swiss cattle: Influence on genetic gain and breeding profit]. Züchtungsk 83, 333-349 [in German]

Kaufmann BA (2007) Cybernetic analysis of socio-biological systems: The case of livestock management in resource-poor environments. Kommunikation und Beratung 81, Margraf Publishers, Weikersheim, Germany

Knol EF, Prins DT (2004) Implementation of selection for carcass quality in a pig breeding program in the Netherlands. AGBU Pigs Genetics Workshop, Armidale, NSW Australia, 41-46

Koch H (1982) [Integrated operative planning]. Gabler Verlag, Wiesbaden, Germany [in German]

König S (2001) [Analysis on a cooperative breeding programme of the breed Holstein-Friesian]. Cuvillier Verlag, Göttingen, Germany [in German]

König S, Lessner S, Simianer H (2007) Application of controlling instruments for improvements in cow sire selection. J Dairy Sci 90, 1967-1980

König S, Simianer H, Willam A (2009) Economic evaluation of genomic breeding programs. J Dairy Sci 92, 382-391

Lehner F, Wildner S, Scholz M (2008) Business informatics. 2nd ed., Carl Hanser Verlag, München/Wien, Germany/Austria

Lemke U (2006) Characterisation of smallholder pig production systems in mountainous areas of North Vietnam. Thesis, Univ Hohenheim, Stuttgart, Germany 
Lush JL (1945) Animal Breeding Plans. 3rd ed., Collegiate Press, Ames, IO, USA

Markemann A, Valle Zárate A (2009) Traditional llama husbandry and breeding management in the Ayopaya region, Bolivia. Trop Anim Health Prod 42, 79-87

Markemann A, Stemmer A, Siegmund-Schultze M, Piepho H-P, Valle Zárate A (2009) Stated preferences of llama keeping functions in Bolivia. Livest Sci 124,119-125

Mburu J, Birner R (2002) Analyzing the efficiency of collaborative wildlife management: The case of two community wildlife sanctuaries in Kenya. J Organ Theory Behav 5, 359-397

Momm H (1972) [Analysis on the consequences of population genetic methods on the organisation of cattle breeding]. Verlag M \& H Schaper, Hannover, Germany [in German]

Müller U (1994) [Breeding planning calculations for optimising breeding systems for improving the fattening performance and the carcass quality of the Merino Meat sheep using ultrasound measurement at living animals]. Thesis, Univ Leipzig, Leipzig, Germany [in German]

Nakimbugwe $\mathrm{H}$ (2005) Open nucleus dairy cattle breeding programme in the Lake Victoria crescent region of Uganda. Thesis, Univ Wien, Vienna, Austria

Neuner S, Götz KU (2011) [Implications of genomic selection on genetic progress in functional traits]. Züchtungsk 83, 350-360 [in German]

Niebel E (1973) [Methodology of breeding planning for purebreeding in cattle from an economic point of view]. Presentation DGfZ-committee for genetic-statistic methods in animal breeding, Biberach, Germany [in German]

Niebel E, Fewson D (1976) [Analysis of breeding planning for purebreeding in dual-purpose cattle. 1. Selection intensity with restricted testing units]. Züchtungsk 48, 3-9 [in German]

Niebel E, Fewson D (1979) [Analysis for optimising breeding planning for purebreeding in pigs. 1. Planning approach and optimising criteria]. Züchtungsk 51, 1-12 [in German]

Nitter G, Graser HU (1994) ZPLAN - a PC program to optimize livestock selection programs. Proc 5th WCGALP, Guelph, Canada, 22, 77-78

Nitter G, Bartenschlager H, Karras K, Niebel E, Graser HU (2000) ZPLAN - a PC computer program to optimize livestock selection schemes. Univ Hohenheim, Stuttgart, Germany

Olesen I, Groen AF, Gjerde B (2000) Definition of animal breeding goals for sustainable production systems. J Anim Sci 78, 570-582

Olivier J, Moyo JS, Montaldo HH, Thorpe W, Valle Zárate A, Trivedi KR (2002) Integrating genetic improvement into livestock development in medium- to low-input production systems. Proc 7th WCGALP, Montpellier, France, No. 25-15

Rewe TO, Herold P, Piepho HP, Kahi AK, Valle Zárate A (2010) Genetic and economic evaluation of a basic breeding programme for Kenya Boran cattle. Trop Anim Health Prod 42, 327-340

Roessler R (2009) Optimising breeding programmes with local pig breeds in North Vietnam considering functions of pigs for smallholders and logistic determinants. Thesis, Univ Hohenheim, Stuttgart, Germany

Roessler R, Drucker AG, Scarpa R, Markemann A, Lemke U, Thuy LT, Valle Zárate A (2008) Using choice experiments to assess smallholder farmers' preferences for pig breeding traits in different production systems in North-West Vietnam. Ecol Econ 66, 184-192

Roessler R, Herold P, Willam A, Piepho HP, Thuy LT, Valle Zárate A (2009) Modelling of a recording scheme for market-oriented smallholder pig producers in Northwest Vietnam. Livest Sci 123, 241-248

Roosen J, Fadlaoui A, Bertaglia M (2005) Economic evaluation for conservation of farm animal genetic resources. J Anim Breed Gen 122, 217-228

Rutten MJM, Bijma P (2001) SelAction Description of the program. Wageningen University Wagenigen, The Netherlands, http://www.anslab.iastate.edu/Class/AnS652X/SELACT/resource/description.pdf [last accessed 10.09.2012]

Rutten MJM, Bijma P, Woolliams JA, van Arendonk JAM (2002) SelAction: Software to predict selection response and rate of inbreeding in livestock breeding programs. J Hered 93, 456-458 
Shook GE (2006) Major advances in determining appropriate selection goals. J Dairy Sci 89, 1349-1361

Swan AA, Brown DJ, Banks RG (2009) Genetic progress in the Australian sheep industry. Proc Assoc Advmt Anim Breed Genet 18, 326-329

Taeubert H, Reinhardt F, Simianer H (2010) ZPLAN+ A new software to evaluate and optimize breeding programs. Proc 9th WCGALP, Leipzig, Germany

Timmermann M (1975) [The simulation of an integrated planning system - combination of quality and quantity based business operations]. In: Wild J (ed.) [Corporate planning]. Rowohlt, Reinbeck bei Hamburg, Germany, 207-222 [in German]

Valle Zárate A (1996) Breeding strategies for marginal regions in the tropics and subtropics Anim Res Devel 43/44, 99-118

Valle Zárate A, Markemann A (2010) Community-based breeding programmes incorporating local breeds: Concept research results and implementation strategy on pigs in Northern Vietnam. Proc 9th WCGALP, Leipzig, Germany

Warui HM (2008) Characterisation of local sheep and goat resources of northern Kenya in their production system context, Thesis, Univ Hohenheim, Stuttgart, Germany

Willam A, Egger-Danner C, Soelkner J, Gierzinger E (2002) Optimization of progeny testing schemes when functional traits play an important role in the total merit index. Livest Prod Sci 77, 217-225

Willam A, Nitter G, Bartenschlager H, Karras K, Niebel E, Graser HU (2008) ZPLAN - a PC computer program to optimize livestock selection schemes, Univ Hohenheim, Stuttgart, Germany

Williamson OE (2008) Outsourcing: Transaction cost economics and supply chain management. J Supply Chain Manage 44, 5-16

Wolfová M, Nitter G (2004) Relative economic weights of maternal versus direct traits in breeding schemes. Livest Prod Sci 88, 117-127

Wolfová M, Nitter G, Wolf J, Fiedler J (2001) Impact of crossing system on relative economic weights of traits in purebred pig populations. J Anim Breed Genet 118, 389-402

Wuensch U (1998) [Analysis of breeding planning in a three-breed-crossing system on the example of the Saxonian Pig Breeders Association e.V.]. Thesis, Univ Hohenheim, Stuttgart, Germany [in German]

Wurzinger M, Willam A, Delgado J, Nuernberg M, Valle Zárate A, Stemmer A, Ugarte G, Soelkner J (2008) Design of a village breeding programme for a llama population in the High Andes in Bolivia. J Anim Breed Genet 125, 311-319

Zeddies J (1973) [About the economic planning and evaluation of cattle breeding programmes]. Habilitation, Univ Göttingen, Germany [in German]

Zeddies J, Weniger JH (1970) [The performance increase in livestock production. 2nd communication: About the maximisation of genetic gain with selection]. Züchtungsk 42, 244-259 [in German]

Zerehdaran S, Hassani S, Gharebash AM, Khanahmadi A, Farivar F (2009) A breeding program for balanced improvement of performance and health in broilers. Pak J Biol Sci 12, 79-82

Zumbach B, Peters KJ (2007) [Breeding programme design for German Fawn goats]. Züchtungsk 79, 184-197 [in German]

Corresponding author:

Pera Herold

email: pera.herold@lgl.bwl.de

Landesamt für Geoinformation und Landentwicklung, Stuttgarter Str. 161, 70806 Kornwestheim, Germany 